\section{Adenomas Hipofisários Produtores de Glicoproteinas: Patogênese, Diagnóstico e Tratamento}

\section{RESUMO}

Os adenomas hipofisários produtores de glicoproteínas compreendem duas entidades clínicas e patológicas distintas: os adenomas gonadotróficos e os tirotróficos. Embora possam ser agrupados por produzirem hormônios e/ou sub-unidades que são glicoproteínas, esses tumores se originam em tipos celulares distintos (gonadotrofos e tirotrofos) que são apenas remotamente relacionados. Os gonadotróficos estão entre os adenomas hipofisários mais comuns, correspondendo à grande maioria dos assim chamados adenomas "não-funcionantes", silenciosos ou clinicamente não-secretores, enquanto os tirotróficos são extremamente raros e clinicamente se apresentam com hipertiroidismo por secreção inapropriada de TSH. Nesse artigo, os autores revisam aspectos epidemiológicos, patológicos, patogenéticos, clínicos, diagnósticos e terapêuticos desses adenomas. Uma ênfase maior foi dada à patogênese molecular dos tumores hipofisários em geral, buscando, sempre que possivel, contrastar as alterações moleculares encontradas nesses adenomas com outros tipos de adenomas hipofisários. No lado mais prático, a experiência dos autores de mais de duas décadas no diagnóstico e tratamento desses tumores na Unidade de Neuroendocrinologia da Unifesp, foi criteriosamente utilizada para discutir a literatura disponível nesses tópicos. (Arq Bras Endocrinol Metab 2005;49/5:657-673)

Descritores: Adenoma hipofisário produtor de glicoproteína; Adenoma gonadotrófico; Adenoma tirotrófico

\begin{abstract}
Glycoprotein-Secreting Pituitary Adenomas: Pathogenesis, Diagnosis and Treatment.

The glycoprotein-secreting pituitary adenomas comprise two distinctive clinical and pathological entities, the gonadotroph and the thyrotroph cell pituitary adenomas. Although they can be grouped together for producing hormones and/or subunits that are glycoproteins, these fumors originate from distinctive cell types (gonadotrophes and thyrotrophes) that are only remotely related. Gonadotroph cell adenomas are among the commonest types of pituitary adenomas, corresponding to the majority of the socalled "nonfunctioning" or clinically silent adenomas, while thyrotroph cell adenomas are extremely rare and usually present with hyperthyroidism due to inappropriate TSH secretion. In this article, we review the literature covering epidemiological, pathological, pathogenetic, clinical, diagnostic and therapeutic aspects of gonadotroph and thyrotroph cell adenomas. Greater emphasis was given to the growing field of molecular pathogenesis of pituitary tumors in general, and a special effort was made to contrast molecular alterations found in these tumors with other tumor types. On the practical side, the authors' extensive experience for more than two decades in the diagnosis and management of these tumors at the Neuroendocrine Unit (Endocrinology Division, Unifesp) was used to balance the extensive literature on this subject. (Arq Bras Endocrinol Metab 2005;49/5:657-673)
\end{abstract}

Keywords: Glycoprotein-secreting pituitary adenoma; Gonadotroph cell adenoma; Thyrotroph cell adenoma

Arq Bras Endocrinol Metab vol 49 n 5 Outubro 2005

\section{atualização}

\author{
Julio Abucham \\ Teresa C. Vieiva
}

Unidade de Neuroendocrinologia da Disciplina de Endocrinologia da Universidade Federal de São Paulo/Escola Paulista de Medicina - UNIFESP/EPM, São Paulo, SP.
Recebido em 08/08/05

Revisado em 25/08/05 Aceito em 29/08/05 
O HORMÔNIOS GLICOPROTÊICOS hipofisários LH, FSH e TSH - são constituídos por duas subunidades ou cadeias, codificadas por genes distintos, sendo a cadeia alfa comum e as cadeias beta diferentes em cada um deles. São produzidos e secretados em dois tipos celulares distintos da hipófise, os gonadotrofos, que produzem LH e FSH, e os tirotrofos, que produzem TSH. Em condições fisiológicas, uma pequena quantidade das sub-unidades livres é também co-secretada por essas células.

Embora gonadotrofos e tirotrofos possuam em comum apenas uma derivação celular remota na ontogênese hipofisária e os adenomas originados de células gonadotróficas e tirotróficas sejam fenotipicamente bem distintos, pode-se agrupá-los como adenomas produtores de glicoproteínas simplesmente por produzirem hormônios glicoprotêicos e/ou suas subunidades. Em contrapartida, é marcante o contraste de alguns aspectos epidemiológicos e clínicos desses tumores: enquanto os adenomas gonadotróficos são os tumores hipofisários mais comuns, apresentando-se geralmente como adenomas clinicamente não secretores, os adenomas tirotróficos são os mais raros, e apresentam, em geral, quadro clínico evidente de hipertiroidismo.

\section{ADENOMAS GONADOTRÓFICOS}

Os adenomas gonadotróficos representam cerca de $30 \%$ dos adenomas hipofisários, acometendo igualmente ambos os sexos, com pico de incidência entre a quinta e a sexta décadas de vida. Assim como outros adenomas hipofisários, podem ser classificados, radiologicamente, de acordo com o tamanho, em microadenomas $(<10 \mathrm{~mm})$ e macroadenomas $(>10 \mathrm{~mm})$. Na prática, constituem a grande maioria dos adenomas clinicamente não funcionantes ou não secretores, sendo assim denominados porque geralmente não apresentam quadro clínico de hipersecreção hormonal, embora quase sempre produzam e secretem hormônios ou sub-unidades hormonais.

\section{Patologia}

A produção hormonal dos adenomas clinicamente não secretores pode ser ocasionalmente observada in vivo, através de dosagens séricas das gonadotrofinas e das suas sub-unidades, no estado basal ou após estímulo com TRH $(1,2)$ ou, mais freqüentemente, in vitro, através de imuno-histoquímica. Além disso, a dosagem de hormônios/sub-unidades em meio de cultura dessas células tumorais, ou a pesquisa de RNA men- sageiro das sub-unidades das gonadotrofinas nesses tumores têm confirmado a natureza gonadotrófica da grande maioria dos adenomas clinicamente não secretores (3-6).

Na patologia convencional, a maioria dos adenomas clinicamente não secretores é do tipo cromófobo, o que aparentemente estaria de acordo com a impressão clínica de que esses tumores não produzem hormônios. Contudo, tanto a microscopia eletrônica como a imuno-histoquímica mostram a presença de grânulos secretórios com conteúdo hormonal variado. A maioria apresenta imuno-histoquímica positiva para um ou mais de um hormônio glicoprotêico hipofisário e/ou subunidade hormonal $(7,8)$. Conforme já discutido, existe um nítido predomínio dos tumores da linhagem gonadotrófica (gonadotrofinomas silenciosos) entre os adenomas clinicamente não secretores, os quais expressam uma ou ambas sub-unidades $\gamma$ das gonadotrofinas $(\gamma$-FSH e $\gamma$-LH), com ou sem co-expressão da subunidade $\gamma$. É interessante que, mesmo os adenomas sem evidência de produção hormonal pela imuno-histoquímica, o que os classificaria como adenomas de células nulas, também pertencem à linhagem gonadotrófica, posto que expressam RNAm para as sub-unidades das gonadotrofinas e secretam gonadotrofinas e/ou subunidades quando colocados em cultura (4-6). A diferenciação entre esses adenomas gonadotróficos e os verdadeiros adenomas de células nulas pode ser feita através da pesquisa imuno-histoquímica do SF-1 (steroidogenic factor), um fator de transcrição específico das células gonadotróficas (9). A degeneração oncocítica, que se caracteriza histologicamente por um citoplasma granular acidófilo abundante e, na microscopia eletrônica, por grande acúmulo de mitocôndrias, é muito mais comum nos adenomas gonadotróficos silenciosos do que em outros adenomas hipofisários, sendo esses tumores classificados como oncocitomas.

Em alguns adenomas clinicamente silenciosos pode-se observar, também pela imuno-histoquímica, a produção de GH, PRL, ACTH, ou TSH, sendo então denominados, respectivamente, somatotrofinomas, prolactinomas, corticotrofinomas, ou tirotrofinomas silenciosos. Nesses casos, a produção não se acompanha de secreção hormonal ou essa é tão pequena que não causa elevação dos níveis hormonais circulantes nem sintomatologia facilmente reconhecível. Por fim, alguns adenomas não secretores são pluri-hormonais, produzindo vários hormônios, por vezes não relacionados, conforme observado pela imuno-histoquímica.

Em nossa casuística de adenomas clinicamente não secretores analisados através da imuno-histoquímica, observamos a presença de pelo menos um hormônio 
hipofisário ou sub-unidade hormonal em cerca de 70\% desses tumores. Desses, a quase totalidade expressa pelo menos uma sub-unidade $\gamma$ de uma das gonadotrofinas hipofisárias e muitos co-expressam a sub-unidade a comum aos hormônios glicoprotêicos (7). O achado imuno-histoquímico mais freqüente é a combinação de uma ou ambas sub-unidades $\gamma$ com a sub-unidade $\gamma$, seguido da presença de apenas uma sub-unidade $\gamma$, e mais raramente pela presença da sub-unidade $\gamma$ isoladamente.

$\mathrm{Na}$ análise dos achados imuno-histoquímicos e dos respectivos níveis séricos das gonadotrofinas e subunidades, observa-se que o grupo de pacientes cujos adenomas são imunopositivos para gonadotrofinas/ sub-unidades apresenta níveis séricos dessas gonadotrofinas/sub-unidades significativamente mais elevados do que o grupo de pacientes cujos adenomas são imunonegativos, embora os níveis individuais sejam geralmente normais (7). Portanto, esses adenomas apresentam alguma secreção hormonal não só in vitro como também in vivo, porém extremamente ineficiente quando comparada à secreção do gonadotrofo normal do adulto, o que impede que os níveis séricos basais de gonadotrofinas/sub-unidades se apresentem elevados na grande maioria dos pacientes. A atividade biológica das gonadotrofinas produzidas por esses adenomas está, via de regra, preservada (10).

\section{Patogênese molecular}

A patogênese dos adenomas produtores de gonadotrofinas, assim como dos outros tipos de adenomas hipofisários, ainda não está totalmente esclarecida. A demonstração de que os vários tipos de adenomas hipofisários são constituídos por proliferações celulares de natureza monoclonal representou uma ruptura com a hipótese da origem hipotalâmica do estímulo oncogênico inicial e concentrou a pesquisa da patogênese na própria célula hipofisária. A pesquisa molecular nessa área tem sido prolífica em encontrar alterações, algumas relativamente específicas de determinados adenomas. O significado da maioria dessas alterações ainda não está claro, mas é provável que muitas delas não sejam verdadeiramente patogenéticas, mas apenas fenômenos secundários no processo de tumorigênese hipofisária. Essas alterações compreendem mutações, hiperexpressão e hipoexpressão de genes que codificam proteínas direta ou indiretamente envolvidas no controle da proliferação celular e/ou da expressão hormonal conforme discutido a seguir.

\section{Genes e proteínas associadas ao ciclo celu- Iar}

O ciclo celular compreende os processos pelos quais as células crescem, duplicam seu genoma e se dividem.
Esse ciclo é controlado por proteínas que atuam na divisão, diferenciação, crescimento e apoptose celular. Essas proteínas, que incluem ciclinas $(\mathrm{C})$, proteínas kinases dependentes de ciclinas (CDK), seus inibidores (CDKI) e outras, podem ser ativadoras ou inibidoras do ciclo celular. As ativadoras são as ciclinas (C), as kinases dependentes de ciclinas (CDKs) e a proteína do gene transformador de tumor hipofisário (PTTG). As proteínas inibidoras compreendem a "família p21" de inibidoras das ciclinas (p21, p27, p57), a "família p16" de inibidoras das kinases dependentes de ciclinas (INK) (pl5INK4b, pl8INK4c e pl9INK4d), além das proteínas RBl, p53 e hZAC. Mutações nos genes dessas proteínas podem descontrolar o ciclo celular e induzir tumorigênese.

\section{Ciclinas e CDKs}

Já foram identificadas seis ciclinas (A-E). As ciclinas A, $\mathrm{B}, \mathrm{D}$ e E são ativadoras do ciclo celular que agem em conjunto com as CDKs estimulando a passagem da fase G1 para S e de G2 para M (checkpoints). Na fase de descanso da divisão (G0), as ciclinas A e E estão inibidas pelas proteínas da "família p21" e pela proteína RBI desfosforilada que se liga a fatores de transcrição e reprime o ciclo em Gl. Paralelamente, CDK4 e CDK6 mantêm-se ligadas a seus inibidores pl6 e indisponíveis para se completar com as ciclinas D.

O envolvimento das ciclinas tem sido evidenciado em inúmeros estudos nos diversos adenomas hipofisários, sendo a superexpressão o achado mais freqüente (11). A ciclina $\mathrm{D}$, codificada pelo gene CCNDI (cromossomo llql3) tem apenas uma pequena e restrita expressão no núcleo celular das células da hipófise normal (12). A expressão nuclear das ciclinas A, B, D e E é maior nos adenomas não funcionantes comparados aos funcionantes, bem como nos macroadenomas em relação aos microadenomas (11). Como não se encontrou superexpressão diferencial entre essas ciclinas, é provável que esses achados decorram de estimulação mitogênica uniforme e não de desbalanço na regulação do ciclo celular. Além disso, uma maior expressão nuclear das ciclinas D e E tem sido observada em adenomas mais agressivos, funcionantes e não funcionantes (12).

\section{PITG (pituitary tumor transforming gene pro - tein)}

O gene PTTG (cromossomo 5q33) codifica a PTTG, uma securina de 202 aminoácidos altamente expressa em células com atividade proliferativa. Durante o ciclo celular, a PTTG contribui para a separação das cromátides irmãs durante a anáfase, após o que é 
degradada, reaparecendo no início da fase $\mathrm{S}$ e atingindo um pico de expressão entre G2 e M. A PTTG também interage com a p53, inibindo sua capacidade de induzir apoptose, além de induzir a expressão do FGF (fator de crescimento de fibroblasto), um mediador do crescimento celular e estimulador da angiogênese que tem sido implicado na patogênese de tumores hipofisários (13). Mutações da PTTG poderiam interferir no processo de separação das cromátides irmãs, gerando instabilidade cromossômica que propiciaria o desenvolvimento de tumores (14).

Uma alta expressão do PTTG tem sido encontrada em adenomas não funcionantes, somatotrofinomas e prolactinomas, mas nenhuma mutação desse gene tem sido observada. Assim, o mecanismo da superexpressão deste gene nos tumores hipofisários ainda permanece desconhecido $(15,16)$.

\section{"Familia p21" de inibidores de ciclinas e "família p16" de inibidores de CDKs}

As proteínas p21, p57 e p27 impedem a progressão do ciclo celular através dos pontos de restrição (check points), comportando-se como supressoras de tumor. Essas proteínas inibem a formação de complexos estimuladores de mitose do tipo ciclina-kinase ciclinadependente (C-CDK), impedindo a progressão do ciclo celular. Quando estímulos mitogênicos desencadeiam a formação de certos complexos de ciclina$\mathrm{CDK}$, como o C-CDK4/6, estes seqüestram as proteínas inibidoras da família p21 de outros complexos, como o D-CDK2 que, liberados dessas proteínas, ativam o ciclo celular (17).

Não se observaram anormalidades na seqüência dos genes que codificam as proteínas p27 e p21, nem diminuição da expressão dessas proteínas, em adenomas não secretores, somatotrofinomas, prolactinomas e corticotrofinomas humanos, mas alguns adenomas corticotróficos apresentam menor expressão imunohistoquímica da p27 em relação ao tecido hipofisário normal (18-20).

A proteína pl6, um potente inibidor da $\mathrm{CDK}$, é codificada pelo gene supressor de tumor CDKN2A ou INK4/MTS (cromossomo 9p21). Essa proteína se liga à CDK4 e impede a formação do complexo ciclina D-CDK4. Na ausência deste complexo, a proteína RBI não é fosforilada e retém os fatores de transcrição necessários à progressão do ciclo celular. Deleções em homozigose do gene CDKN2A ou seu silenciamento através da hipermetilação de "ilhas $\mathrm{CpG}$ " na região promotora têm sido associados a vários tumores $\mathrm{em}$ animais e humanos (21).

Os adenomas hipofisários freqüentemente apre- sentam baixa expressão da proteína pl6, um potente inibidor da CDK (22), mas raramente exibem perda da heterozigosidade de $9 \mathrm{p} 21$, o locus do gene CDKN2A (22). Além disso, nenhuma mutação na região codificadora desse gene tem sido observada nesses adenomas. No entanto, hipermetilação da região promotora desse gene tem sido encontrada na maioria dos adenomas não funcionantes, mas em apenas $10 \%$ dos somatotrofinomas. A maioria desses adenomas também apresenta expressão imuno-histoquímica diminuída da pl6, indicando que a hipermetilação possa ser um mecanismo de silenciamento gênico importante na patogênese dos gonadotrofinomas (23).

\section{Proteína RB 1}

A proteína RBl é codificada pelo gene supressor de tumor RBI (13q14.2). Essa proteína tem papel importante no checkpoint Gl do ciclo celular: na forma ativa (hipofosforilada), impede a progressão do ciclo ligando-se a fatores de transcrição. Quando fosforilada, inativa-se e libera fatores de transcrição necessários para que o ciclo celular prossiga. No retinoblastoma familiar, os pacientes herdam uma mutação germinativa do gene RBl em heterozigose e desenvolvem tumores retinianos quando perdem essa heterozigosidade ( $\mathrm{LOH}$, loss of heterozygosity). Além disso, apresentam predisposição para vários outros tumores ao longo da vida, mas não para adenomas hipofisários. Em adenomas hipofisários esporádicos, incluindo os gonadotrofinomas, não foram encontradas mutações, deleções ou perda alélica do gene RBl (24-28).

\section{Proteína p53}

O p53 (cromossomo 17pl3.1) é um gene supressor de tumor que codifica a proteína p53, uma fosfoproteína nuclear que induz a parada do ciclo celular em Gl até que a integridade do genoma esteja checada e assegurada. Caso contrário, a p53 é capaz de ativar mecanismos de apoptose (29). Mutações germinativas do gene p53 causam a síndrome de Li-Fraumeni, caracterizada por múltiplos cânceres, e mutações somáticas neste gene são comumente encontradas em tumores esporádicos de pulmão, esôfago, cólon, cérebro, mamas, pele e outros.

Adenomas e adenocarcinomas hipofisários e suas respectivas metástases não apresentam mutações no $p 53(30,31)$, mas os índices de proliferação celular e a expressão da p53 tendem a ser mais altos em metástases do que em tumores primários (32).

\section{Proteína hZAC}

O gene $h Z a c$ (cromossomo 6q24-q25), é um gene 
supressor de tumor (33) que codifica uma proteína zinc finger (ZAC) capaz de induzir a parada do ciclo celular em Gl, à semelhança da p53, mas com maior capacidade de induzir apoptose porque atua em qualquer fase do ciclo celular. A maior expressão dessa proteína tem sido encontrada nas células hipofisárias normais. Mutações desse gene não têm sido encontradas em adenomas hipofisários, mas redução do RNAm e da proteína têm sido observados em alguns adenomas não funcionantes (34).

\section{GENES E PROTEÍNAS ASSOCIADAS À SINALIZAÇĀO INTRACELULAR}

\section{Proteínas G}

As proteínas G (guanine nucleotide-binding proteins) são heterotrímeros constituídas por sub-unidades alfa, beta e gama, presentes em todas as células do organismo e altamente conservadas na evolução. Existem pelo menos duas classes: estimulatória (Gs) e inibitória (Gi), cujas sub-unidades alfa podem estimular (Gs$\gamma)(20 \mathrm{q} 13.2)$ ou inibir $(\mathrm{Gi} 2-\gamma)(3 \mathrm{p} 21)$ a atividade da adenilciclase. Na conformação trimérica, a sub-unidade alfa é inativa e liga um GDP (difosfato de guanosina). $A$ ativação de um receptor acoplado à proteína $G$ por um sinal extracelular promove a troca do GDP pelo GTP, dissociando a sub-unidade alfa, que então interage com moléculas efetoras como a adenilciclase, aumentando (Gs) ou inibindo (Gi) $\gamma$ conversão de ATP em AMP cíclico. Este, por sua vez, ativa as vias de sinalização dependentes (PKA/CREB), estimulando síntese hormonal, proliferação celular e outros processos. A proteína $\mathrm{G}$ é autodesativada pela presença de atividade de GTPase intrínseca da sub-unidade alfa.

GNAS1: Mutações ativadoras nos exons 8 e 9 do gene GNASI (mutações gsp) resultam na substituição de um aminoácido na proteína Gs- $\gamma$ (codons 201 e 227 respectivamente), tornando-a constitutivamente ativa por perder a capacidade intrínseca de hidrolisar o GTP. Essa mutação transforma o proto-oncogene GNASI no oncogene gsp. Mutações gsp têm sido freqüentemente encontradas em até $43 \%$ dos adenomas somatotróficos, dependendo da região geográfica, mas em apenas 10\% dos adenomas não secretores (35-38).

GNAIS2: A somatostatina inibe a proliferação dos somatotrofos através de ligação aos receptores acoplados à proteína Gi2-alfa na membrana celular. Isso motivou a pesquisa de mutações inativadoras no gene GNAIS2 em adenomas hipofisários, tendo-se encontrado mutações em menos de $10 \%$ dos adenomas não-secretores e em nenhum dos somatotrofinomas analisados $(37,38)$.
GNAQ: A proteína G-alfa-q é mediadora da estimulação da fosfolipase C-beta (OMIM 600230), de maneira análoga à estimulação da proteína-kinase $\mathrm{A}$ pela Gs-alfa. Essa proteína é codificada pelo gene GNAQ (9q21). Nenhuma mutação desse gene em adenomas hipofisários, incluindo adenomas secretores de gonadotrofinas e adenomas não-secretores invasivos, tem sido encontrada (39).

\section{Proteína Kinase C (PKC)}

O gene da PKC-alfa (17q22-23.2) codifica uma kinase, presente em todas as células eucarióticas, que tem papel importante na regulação do crescimento e proliferação celular através da fosforilação de proteínas (40). A PKC$\gamma$ tipo III está envolvida na regulação da função hipofisária durante o desenvolvimento glandular bem como na síntese e secreção de hormônios hipofisários (41-44).

A análise da expressão da PKC nos vários adenomas hipofisários tem demonstrado superexpressão nos adenomas não-secretores e nos somatotrofinomas, mais intensamente nos invasivos. No entanto, o aumento da atividade enzimática observado tem sido proporcionalmente menor em relação ao aumento da expressão da proteína, sugerindo disfunção da PKC nesses tumores $(42,44,45)$. Mutações desse gene foram encontradas apenas em alguns adenomas invasivos, incluindo um não-secretor $(40,46,47)$.

\section{Outros oncogenes}

Dos outros oncogenes relacionados à sinalização intracelular como $H$-ras, $N$-rase $K$-ras, myc e $c$-erb, apenas o $H$-ras apresentou mutação em um entre centenas de adenomas hipofisários analisados. Além disso, também estava mutado em três de quatro metástases de carcinomas hipofisários, mas não nos tumores primários (17). Assim, parece que esses oncogenes não estão envolvidos na tumorigênese pituitária, mas poderiam estar relacionados à capacidade de originar metástases.

\section{RECEPTORES DE HORMÔNIOS E DE FATORES DE CRESCIMENTO}

\section{Receptor de dopamina (DRD2)}

Em prolactinomas humanos, responsivos ou não aos agonistas dopaminérgicos, não se encontraram mutações na região codificadora do DRD2 (48). Nesses tumores, a alteração mais freqüente do DRD2 é quantitativa: expressão reduzida, desbalanço entre formas curtas e longas (derivadas de splicing alternativo do mesmo gene) e redução da ligação aos agonistas dopaminérgicos, sendo essas alterações correla- 
cionadas com a resposta a esses agentes. Nos somatotrofinomas, observa-se a presença de receptores dopaminérgicos tanto curtos como longos, íntegros e com expressão proporcional, porém reduzida. Nos adenomas clinicamente não secretores e nos somatotrofinomas, os receptores dopaminérgicos possuem uma menor afinidade pelo ligante do que nos prolactinomas (49).

\section{Receptor de GHRH (GHRH-R)}

Camundongos transgênicos que superexpressam GHRH desenvolvem, ao longo do tempo, hiperplasia somatotrófica com eventual progressão para adenoma. Contudo, não foram identificadas mutações ativadoras no GHRH-R em adenomas somatotróficos esporádicos ou familiares. Cerca de $20 \%$ das mutações detectadas são inativadoras, enquanto as restantes parecem não modificar a resposta do AMPc ao GHRH (50). Os adenomas somatotróficos freqüentemente superexpressam várias isoformas de GHRH-R e alguns expressam uma forma truncada, não funcionante, desse receptor. Com menor freqüência, adenomas não secretores e produtores de gonadotrofinas também pode apresentar superexpressão do receptor de GHRH (51) (Hashimoto e cols., 1995).

\section{Receptor de TRH (TRH-R)}

Mutações ativadoras no gene do TRH-R não têm sido encontradas em tirotrofinomas, somatotrofinomas, prolactinomas ou adenomas não funcionantes $(52,53)$.

\section{Receptor de GnRH (GnRH-R)}

Nenhuma mutação no gene que codifica o receptor de GnRH foi encontrada em adenomas não secretores, indicando que GnRH-R não tem papel importante na patogênese desses tumores (17).

\section{Receptor de estrógeno (ER)}

Os efeitos fisiológicos do estrógeno na hipófise são mediados pelo receptor nuclear de estrógeno (ER). Esses receptores são expressos em todos os tipos celulares da hipófise normal, com o nível mais elevado nos lactotrofos $(54,55)$. O estrógeno é mitogênico para os lactotrofos e o hiperestrogenismo pode levar à hiperplasia lactotrófica. Camundongos expostos a altas doses de estrógenos durante o período pré-natal desenvolvem hiperplasia e adenoma lactotrófico (13). O envolvimento do estrógeno na tumorigênese hipofisária parece estar relacionado à sua capacidade de estimular, através do ER, a transcrição de genes implicados na tumorigênese pituitária como PTTG, FGF- $\gamma$, $F G F-\gamma R, T G F-\gamma$ e $T G F-\gamma$ (56). Várias isoformas do
ER estão presentes em células hipofisárias normais e tumorais, mas com diferentes níveis de expressão. A maior expressão tem sido observada nos prolactinomas e nos adenomas mamossomatotróficos $(17,57)$ e a menor expressão (isoforma beta) nos adenomas não secretores $(58)$.

\section{Receptores do Fator de Crescimento dos Fibroblastos}

Quatro genes distintos codificam os receptores dos fatores de crescimento dos fibroblastos (FGFRs). Esses receptores são expressos em tecidos normais e possuem uma estrutura protéica semelhante. São constituídos por três domínios extracelulares, sendo dois deles de ligação aos FGFs, um domínio transmembrana e um domínio tirosino kinase intracelular, que se fosforila após a ativação do ligante, recrutando proteínas sinalizadoras. Cada gene, através de splicing alternativo específico, codifica múltiplas isoformas desses receptores, que podem ser secretadas (isoforma I) ou permanecer ligadas à célula (isoforma $\mathrm{K}$ ), resultando em funções específicas dos FGFRs para cada tecido. Os FGFRs ativados por seus ligantes têm atividade mitogênica potente e alterações no padrão de expressão das isoformas podem resultar na formação e progressão tumoral (59).

O padrão de expressão dos vários subtipos de FGFRs na hipófise normal e nos adenomas hipofisários, incluindo os gonadotróficos, demonstra que a hipófise normal expressa as isoformas I e $\mathrm{K}$ dos FGFRs $\mathrm{I}$ - 4, com exceção da isoforma FGFR4 K que é truncada, mas apenas 7,5\% dos adenomas apresentam esse padrão de expressão. Cerca da metade dos adenomas expressam a isoforma $\mathrm{K}$ do FGFR4, o que poderia indicar que esta isoforma esteja relacionada à tumorigênese hipofisária. Não houve correlação entre o padrão de expressão dos FGFRs e o tipo, tamanho ou invasividade tumoral. $\mathrm{O}$ padrão alterado de expressão dos FGFRs nos adenomas hipofisários em relação à hipófise normal pode significar que uma disfunção FGF/FGFR tenha papel na tumorigênese hipofisária (60).

\section{Receptores do Fator Transformador de Crescimento}

Os receptores do fator transformador de crescimento (TGFRs) apresentam atividade serina-treonina-kinase e medeiam a ação dos TGF na diferenciação e proliferação celular. São receptores transmembrana encontrados em 2 isoformas (I e II) codificadas por genes distintos (9q33-34 e 3p22). Os receptores tipo I não têm capacidade de ligação ao TGF, enquanto os do tipo II apresentam grande afinidade pelo ligante e possuem um 
longo domínio citoplasmático com atividade proteínakinase. Quando o TGF- $\gamma$ se liga ao receptor tipo II, ocorre recrutamento do receptor tipo I, formando um complexo heterotetramérico de dois receptores tipo I e dois tipo II. O receptor tipo II fosforila o tipo I que, por sua vez, fosforila outros substratos, incluindo várias proteínas co-transdutoras de sinal que se complexam e ligam ao DNA, regulando (geralmente inibindo) a transcrição gênica (61). Mutações inativadoras no $T G F \gamma-R$ poderiam induzir a tumorigênese por abolir o sinal inibitório da TGFy, mas a análise desses genes em adenomas hipofisários não tem mostrado mutações (59).

\section{FATORES DE CRESCIMENTO}

Alguns fatores de crescimento produzidos na hipófise (fibroblast growth factor, FGFs, TGFs), quando superexpressos em camundongos transgênicos, são capazes de induzir hiperplasia hipofisária que pode evoluir para adenoma, indicando que esses fatores de crescimento possam ter algum papel na tumorigênese pituitária (56).

\section{FGFs (Fatores de Crescimento de Fibroblas- tos)}

A família dos FGFs compreende várias proteínas semelhantes que exercem suas ações através de receptores específicos, os FGFRs. O FGF-2 (basic FGF ou bFGF), codificado pelo gene FGFB (4q25-27), é um fator de crescimento que tem atividade mitogênica, angiogênica e neurotrófica (13). A maior expressão é observada no cérebro e na hipófise. O FGF-2 estimula a secreção de PRL, tanto de células hipofisárias normais quanto adenomatosas. Embora os prolactinomas expressem FGF-2, este fator de crescimento não é mitogênico para as células hipofisárias normais in vivo, e camundongos transgênicos que superexpressam FGF2 não desenvolvem adenomas hipofisários (62).

Estudos recentes demonstraram que $40 \%$ dos pacientes portadores de MEN 1 e a maioria dos pacientes com MEN 1 e adenomas hipofisários não tratados apresentam níveis circulantes de FGF-2 mais altos do que pessoas normais (63). O tratamento cirúrgico ou medicamentoso desses tumores reduz o FGF- 2 circulante, sugerindo que o tumor seja a fonte desse FGF-2. Embora a MEN 1 esteja associada com a perda da heterozigosidade de um gene supressor de tumor, o FGF-2 pode também ter um papel promovendo a tumorigênese hipofisária nesses pacientes, mas a interação exata entre o gene supressor de tumor e o FGF-2 local é desconhecida (64).

O FGF-4 é codificado pelo proto-oncogene hst e é expresso somente em tecido embrionário. Entretanto, alguns tumores malignos como câncer gástrico e de esôfago, expressam esse gene, cuja localização cromossômica (1 lql3) é muito próxima à do gene supressor de tumor da MEN 1. O FGF-4 aumenta a transcrição do gene da PRL e a secreção dos lactotrofos em ratos e, estudos em células GH4 indicam que as células transfectadas com hst formam tumores que são mais agressivos quando transplantados em animais (65). $\mathrm{O}$ estudo imuno-histoquímico do FGF-4 em prolactinomas humanos detectou expressão em 36\% deles, mas apenas em 5\% dos adenomas secretores de GH, ACTH e não secretores, não se observando a expressão de FGF-4 em tecido normal $(66,67)$.

\section{GENES DA SÍNDROME DE NEOPLASIA ENDÓC- RINA MÚLTIPLA TIPO I}

Essa síndrome, transmitida por herança autossômica dominante de baixa penetrância, caracteriza-se pelo desenvolvimento de adenomas em paratiróides, pâncreas e hipófise. O gene $M E N 1$ (1 lq13) codifica a menina, uma proteína nuclear de 610 aminoácidos que interage com várias proteínas supressoras de tumor reprimindo a transativação gênica.

O desenvolvimento de um tumor nos portadores de uma mutação germinativa no gene $M E N 1$ requer que o alelo não afetado sofra uma alteração somática, caracterizando a perda da heterozigosidade $(\mathrm{LOH})$ desse gene. A LOH pode decorrer tanto da perda alélica de todo o locus gênico quanto de simples deleções de pares de bases ou de mutações nonsense que geram uma proteína truncada (56).

Como a perda da heterozigosidade para o locus $11 q 13$ foi observada em adenomas hipofisários esporádicos, especialmente nos invasivos, sugeriu-se que o gene da MEN 1 poderia estar envolvido na progressão desses tumores. Entretanto, o seqüenciamento desse gene nos tumores esporádicos revelou $\mathrm{LOH}$ em apenas $14 \%$ e mutações inativadoras na região codificadora do gene em apenas $1 \%$ deles $(68,69)$. Além disso, como a grande maioria dos adenomas hipofisários esporádicos expressa ambos os alelos 1lq13, um possível imprinting genômico de um dos alelos fica descartado como um possível mecanismo patogenético desses tumores (70).

\section{OUTROS FATORES}

\section{GADD45 gama (growth arrest and DNA damage-inducible gene)}


A proteína GADD45G é codificada pelo gene GADD45-gama (9q22.1-22.2), da família de genes inibidores do crescimento celular. Essa proteína atua após a p53 e a proteína do gene supressor do tumor de mama (BRCAl). O gene GADD45G é ativado pela lesão do DNA e atua como um regulador negativo do crescimento celular. A proteína GADD45G é expressa na placenta, coração, fígado, músculo esquelético e hipófise. Linhagens de tumor hipofisário transfectadas com este gene apresentam redução da proliferação celular (71). A análise da expressão do RNAm do GADD45G em hipófise normal e em adenomas demonstrou que seus transcritos, presentes em grande quantidade nas células hipofisárias normais, estavam geralmente reduzidos nos diversos tipos de tumores hipofisários (71).

\section{Quadro Clínico}

Os adenomas gonadotróficos apresentam-se, em geral, como adenomas clinicamente não secretores. $\mathrm{O}$ diagnóstico é geralmente feito quando atingem um certo volume e comprimem estruturas adjacentes, sobretudo o quiasma óptico, provocando perda visual. Menos freqüentemente, podem também comprimir um ou mais nervos cranianos que atravessam o seio cavernoso e provocar ptose palpebral e/ou oftalmoplegia. Essa apresentação ocorre, em geral, de forma súbita, devido à apoplexia tumoral e, mais raramente, de forma lenta, por invasão tumoral propriamente dita.

Em nossa experiência, o tempo decorrido entre o início dos sintomas e o diagnóstico desses adenomas foi superior a um ano em metade dos pacientes, sendo a perda visual, presente em $84 \%$ dos casos, a principal queixa que levou o paciente à consulta, seguida de cefaléia e mais raramente de déficit hormonal. Em cerca de $10 \%$ dos pacientes o diagnóstico decorreu de estudo radiológico indicado por sintomas não relacionados ao tumor (incidentalomas).

Devido ao tamanho, esses adenomas podem comprimir a adeno-hipófise adjacente, haste hipofisária e mesmo o hipotálamo, provocando hipopituitarismo em graus variados, cujas manifestações clínicas mais comuns são a amenorréia na mulher e a impotência no homem. A deficiência de GH também é muito freqüente, mas suas manifestações sintomáticas são pouco específicas e podem ser confundidas com outras deficiências (hipotiroidismo, hipogonadismo) ou passar despercebidas. As deficiências do setor tirotrófico e adrenocorticotrófico, embora comuns, são geralmente subclínicas ou oligossintomáticas. A compressão da haste e/ou hipotálamo também pode determinar aumento dos níveis de prolactina, que raramente ultra- passam os $100-150 \mathrm{ng} / \mathrm{mL}$, causando ou não galactorréia. Os adenomas não secretores que cursam com hiperprolactinemia têm sido denominados pseudoprolactinomas, para serem diferenciados dos prolactinomas verdadeiros e não serem tratados erroneamente. Ainda que os adenomas clinicamente não secretores freqüentemente se apresentem como macroadenomas de grandes proporções e com grande extensão supraselar, são raros os casos que cursam com hipertensão intracraniana ou diabetes insipidus.

Atualmente, com o uso crescente da tomografia computadorizada e da ressonância magnética de crânio na investigação de inúmeras condições clínicas, tem sido também crescente o número de adenomas hipofisários não secretores que são descobertos em pacientes relativamente ou completamente assintomáticos. Esses "incidentalomas" variam de pequenos microadenomas intra-hipofisários sem significado clínico até macroadenomas com extensão supra-selar e compressão do quiasma óptico.

As dosagens séricas das gonadotrofinas e subunidades apresentam escasso valor no diagnóstico na maioria dos casos de adenomas clinicamente não secretores, posto que a secreção hormonal é muito ineficiente e só ocasionalmente promove o aumento dos níveis séricos basais das gonadotrofinas ou das subunidades. Em nossa experiência, assim como em outras séries que utilizaram ensaios altamente específicos da sub-unidade a livre no soro, aproximadamente $25 \%$ dos pacientes com adenomas não secretores apresentam elevação dos níveis séricos dessa sub-unidade (7274). Uma proporção ainda menor de pacientes apresenta elevação do FSH intacto, sendo a elevação do $\mathrm{LH}$ intacto raramente observada. A dosagem das gonadotrofinas intactas e das sub-unidades $\gamma, \gamma$ - $\mathrm{LH}$ e $\gamma$-FSH após estimulação com TRH aumenta o desempenho diagnóstico, porém raras vezes é necessária. Em mulheres com mais de 45 anos de idade, a elevação concomitante dos níveis séricos de FSH, LH e subunidade a não deve ser interpretada, a princípio, como decorrente do tumor, e sim da menopausa, principalmente se o adenoma não for de grandes proporções. É interessante notar que os níveis séricos de gonadotrofinas em mulheres nessa faixa etária portadoras de adenomas clinicamente não secretores, incluindo os imunopositivos para gonadotrofinas, encontram-se geralmente muito aquém dos níveis esperados para a idade, situando-se freqüentemente na faixa de referência das mulheres em idade fértil ou mesmo abaixo desses valores (7). Isso demonstra não só a ineficiência secretória desses adenomas como também o acentuado comprometimento da reserva gonadotrófica 
hipofisária causado pela compressão tumoral.

São muito raros os gonadotrofinomas clinicamente secretores. No homem adulto, a hipersecreção de FSH pode causar aumento do volume testicular pela proliferação dos túbulos seminíferos e elevação das concentrações da inibina circulante, enquanto a hipersecreção de LH promove aumento dos níveis séricos da testosterona. No homem em idade prépuberal, a hipersecreção de LH pode causar puberdade precoce. Na mulher em idade fértil, a hipersecreção de FSH causa hiperestimulação ovariana, com aumento da inibina circulante, ovários policísticos e hiperestrogenismo com espessamento endometrial e irregularidade menstrual.

\section{Imagem}

$\mathrm{Na} \mathrm{RM}$, os microadenomas apresentam, em geral, intensidade de sinal inferior ao restante do parênquima hipofisário (hipointensos) em $\mathrm{Tl} \mathrm{e}, \mathrm{em} \mathrm{T} 2$ podem, às vezes, apresentar hipersinal em toda sua dimensão. Nos microadenomas, o volume selar pode estar preservado, mas freqüentemente existem alterações do assoalho selar, como desnivelamento, adelgaçamento e erosão, que podem ser mais bem observadas na tomografia computadorizada, especialmente através da "janela óssea”. Os microadenomas freqüentemente deslocam a haste hipofisária para o lado contralateral à lesão e, após injeção do contraste paramagnético, apresentam retardo na captação do contraste em relação à hipófise normal quando observados nos tempos precoces do estudo dinâmico, mas essa diferença pode desaparecer ou mesmo se inverter em tempos mais tardios (75).

Os macroadenomas são freqüentemente heterogêneos em Tl, com áreas de iso-sinal e hipo-sinal, ou mesmo de hipersinal que, em geral, correspondem a focos de hemorragia. Em T2, podem apresentar uma ou mais áreas de sinal mais intenso que não são bem delimitadas em Tl (discretamente hipointensas), correspondendo a áreas císticas com conteúdo líquido. Embora a maioria dos adenomas achados incidentalmente corresponda a microadenomas intra-selares, alguns são macroadenomas com extensão extra-selar, em geral supra-selar e/ou para o seio cavernoso. Nos macroadenomas, a sela turca está freqüentemente alargada e adelgaçada, podendo ser quase virtual, e a distância entre as artérias carótidas internas pode estar aumentada. O envolvimento de uma ou ambas artérias carótidas pelo adenoma invadindo o seio cavernoso não é um achado incomum, mas sintomas vasculares são extremamente raros. Quando os macroadenomas se estendem para a região supra-selar, freqüentemente se observa um acinturamento da massa na altura do diafragma selar, bastante característico, que é de grande utilidade no diagnóstico diferencial dessas lesões (75). Nos macroadenomas, a hipófise normal se impregna mais intensamente e mais precocemente de contraste paramagnético do que o tecido tumoral, encontrando-se, em geral, bastante deformada e deslocada, da mesma forma que o hipersinal neurohipofisário. O diagnóstico diferencial com outras massas da região selar deve ser sempre considerado a partir da imagem e do quadro clínico.

O diagnóstico diferencial dos adenomas clinicamente não secretores com outras patologias não funcionantes da região selar deve ser sempre considerado, levando-se em conta tanto o aspecto da imagem como os dados epidemiológicos, clínicos e laboratoriais do paciente (76).

\section{Tratamento}

Devido ao tamanho relativamente grande desses adenomas e da invasão de estruturas vizinhas por ocasião do diagnóstico, o tratamento dos adenomas gonadotróficos envolve não só cirurgia, mas também radioterapia e em determinados casos e situações, o uso de drogas de eficácia relativamente baixa e/ou ainda não totalmente comprovada.

Nos incidentalomas de localização intra-selar (microadenomas), usualmente sem expansão supraselar, recomenda-se apenas seguimento clínico e de imagem por ressonância magnética anual. O crescimento desses microadenomas é relativamente raro e alguns podem sofrer involução (77). Havendo crescimento significativo, deve-se indicar a cirurgia; se o tamanho da lesão permanecer inalterado por 2 a 3 anos e o paciente continuar assintomático, pode-se aumentar o intervalo entre essas avaliações. Os macroadenomas que se apresentam como incidentalomas também podem, a princípio, ser acompanhados através de imagens periódicas, porém o risco de crescimento dessas lesões é bem maior do que dos microadenomas. Durante o acompanhamento, o aparecimento de alterações campimétricas e/ou a proximidade com o quiasma óptico devem ser utilizados como critério para indicação cirúrgica. A indicação cirúrgica no paciente assintomático pode ser considerada em casos individuais tendo-se em conta a idade e o estado clínico do paciente, bem como os índices de morbidade e mortalidade do cirurgião.

\section{Cirurgia}

A princípio, a cirurgia é o método de escolha para o tratamento dos adenomas clinicamente não secretores, constituindo, até o presente, a maneira mais eficiente e 
rápida para a redução desses tumores. O objetivo cirúrgico é retirar o máximo de massa sem comprometer estruturas adjacentes, promovendo a descompressão imediata das vias ópticas. Após a descompressão cirúrgica, a recuperação visual, completa ou parcial, é observada em $80 \%$ dos casos (78). A ressecção total possibilita a cura do tumor, mas só ocorre nos adenomas sem invasão do seio cavernoso e, com maior freqüência, naqueles com pequena ou nenhuma extensão supra-selar. Na prática, uma redução significativa do volume tumoral é o resultado mais observado após a cirurgia desses adenomas, sendo essa redução, em geral, suficiente para descomprimir as vias ópticas e permitir a recuperação visual. Além disso, a cirurgia mais frequentemente melhora do que deteriora a função hipofisária desses pacientes (79).

A via de acesso para a ressecção dos adenomas não secretores com pequena ou moderada extensão supra-selar deve ser transesfenoidal, mas na presença de grande extensão supra-selar, pode-se utilizar a via transcraniana ou ambas. Dada a baixa morbidade associada à cirurgia pelo acesso transesfenoidal e a possibilidade da massa supra-selar descer ao interior da sela durante a cirurgia, à medida que a parte inferior é ressecada, ou após a cirurgia, o uso da via transesfenoidal é o preferido numa primeira abordagem. Na prática, o sucesso da ressecção tumoral varia diretamente com a experiência e habilidade do neurocirurgião e inversamente com a consistência, aderência, invasão e extensão extra-selar do tumor. Mesmo em mãos experientes, é grande o número de pacientes com resíduo tumoral significativo após a cirurgia. Uma avaliação mais precisa e definitiva do resultado cirúrgico através de ressonância magnética deve ser feita apenas após 3 ou 4 meses da cirurgia. Avaliações mais precoces podem subestimar a real magnitude da ressecção pela presença de material de enchimento e sangue ainda não reabsorvidos na cavidade cirúrgica.

\section{Radioterapia}

A radioterapia como forma de tratamento inicial dos adenomas clinicamente não secretores é reservada para pacientes com contra-indicação cirúrgica ou que recusem cirurgia. A radioterapia é mais utilizada como tratamento complementar à cirurgia, mas sua indicação deve ser individualizada e não rotineira para controlar o crescimento do resíduo tumoral. Em nossa experiência, se o remanescente tumoral após a cirurgia for pequeno, é possível acompanhar sua evolução através de exames periódicos de imagem e indicar a radioterapia ou uma nova intervenção cirúrgica apenas quando houver evidência de crescimento. Como o ritmo de crescimen- to é freqüientemente muito lento e às vezes nulo, essa conduta pode postergar por muitos anos ou mesmo evitar o hipopituitarismo e a reposição hormonal, bem como outros efeitos indesejáveis da radioterapia em muitos pacientes. Nesse período, o uso de agonistas dopaminérgicos parece contribuir para a redução ou estabilização do crescimento do remanescente tumoral em grande parte dos pacientes com adenomas gonadotróficos (80). Em nossa opinião, apesar de a radioterapia ser muito eficiente no controle do crescimento tumoral, deve ser utilizada apenas nos resíduos de adenomas cujas chances de resolução cirúrgica tenham sido competentemente exploradas e cujo ritmo de crescimento, observado após o tratamento cirúrgico inicial, represente risco neuro-oftalmológico apreciável, e não como tratamento complementar rotineiro para ressecções tumorais mal executadas.

A dose de radioterapia convencional para o tratamento dos adenomas hipofisários, secretores ou não secretores, é de 45 a 50 Gy, fracionados em 25 a 30 aplicações diárias de 150 a 200 rads, através de três ou mais portas de entrada para se reduzir a irradiação sobre o sistema nervoso central. Os efeitos sintomáticos agudos da radioterapia são facilmente contornáveis com uso temporário de antieméticos e glicocorticóides. O efeito máximo na redução tumoral só é visto, em geral, após meses ou anos da aplicação. $\mathrm{O}$ crescimento do resíduo tumoral ("recidiva") pode chegar a $20 \%$ ao longo de 20 anos, sendo mais freqüente nos primeiros cinco anos após a radioterapia. Assim, um seguimento periódico com imagem, mais freqüente nos primeiros anos, é necessário para surpreender um eventual crescimento do tumor.

O hipopituitarismo é uma complicação comum cuja prevalência se acumula ao longo de muitos anos e mesmo décadas após a radioterapia, durante os quais a função hipofisária deverá ser periodicamente avaliada para orientar a reposição hormonal. Outras complicações da radioterapia, bem mais raras do que o hipopituitarismo, incluem a atrofia cerebral, o desenvolvimento de outros tumores no sistema nervoso central, principalmente meningeomas, e a necrose cerebral. Os efeitos da radioterapia em funções cognitivas e no comportamento têm sido pouco estudados, mas existem evidências quanto a esses efeitos que não são devidamente avaliados na rotina clínica (81).

$\mathrm{O}$ uso da assim chamada "radiocirurgia estereotáxica" para o tratamento de resíduos tumorais é muito atraente, aguardando maior experiência e disponibilidade para ser mais difundido. Em alguns centros, essa modalidade tem substituído com sucesso a radioterapia convencional no controle do crescimento 
de restos tumorais. Apresenta vantagens sobre a radioterapia convencional, sobretudo por liberar uma elevada dose de irradiação, geralmente necrotizante, com alto grau de precisão sobre a área do tumor, numa única sessão, com irradiação mínima de outras áreas do sistema nervoso central (81).

Tecnicamente, a radiocirurgia estereotáxica pode ser realizada de três formas: (1) usando-se um feixe rotacional de fótons gerado por um acelerador linear e focalizado sobre um ponto estacionário; (2) usando-se vários feixes de radiação gama (Cobalto$60)$, aplicados através de uma grande quantidade de portas de entrada e convergentes num ponto fixo; (3) usando-se um feixe de partículas pesadas carregadas (prótons), geradas por um ciclotron, que liberam radiação quando param ("Bragg peak”). Dessas, a modalidade mais promissora é a terapia denominada "gama knife", que administra simultaneamente até 201 feixes convergentes de radiação ionizante a partir de fontes de Cobalto-60 no alvo tumoral.

Além da disponibilidade ainda limitada de centros especializados em radiocirurgia estereotáxica, o tamanho do resíduo tumoral e sua proximidade com o quiasma óptico constituem as limitações mais críticas para seu uso. Atualmente, a indicação mais precisa para o uso dessa modalidade de radioterapia é no tratamento do resíduo tumoral em seio cavernoso, em geral inabordável pela cirurgia. Dada a relativa insensibilidade das estruturas que percorrem o seio cavernoso à irradiação, doses maiores podem ser administradas com relativa segurança nessa região (81).

\section{Tratamento Farmacológico}

Ao contrário dos prolactinomas e dos tumores produtores de hormônio de crescimento, não existe ainda nenhum tratamento farmacológico específico para os adenomas clinicamente não secretores. A despeito da origem gonadotrófica da maioria desses tumores, tanto os superagonistas como os antagonistas do receptor do GnRH mostraram-se ineficazes para seu tratamento (82). Por outro lado, a demonstração in vitro e in vivo de receptores de dopamina e de somatostatina em grande parte desses adenomas, juntamente com a disponibilidade de agonistas dopaminérgicos e somatostatinérgicos para uso clínico têm mantido o interesse de se procurar o valor terapêutico real desses agentes no tratamento dos adenomas clinicamente não secretores $(83,84)$.

A utilização de bromocriptina pode reduzir a massa em alguns casos e melhorar a perda visual, mas o efeito é imprevisível, de magnitude muito menor e bem mais tardio do que nos prolactinomas (82). Mais recentemente, a cabergolina pela sua maior potência e tolerância em relação à bromocriptina, tem substituído a bromocriptina no tratamento dos adenomas clinicamente não funcionantes, mas seus resultados na redução tumoral também são modestos (83). Da mesma forma, o uso de análogos da somatostatina, sobretudo o octreotídeo, tem mostrado pouca eficiência na redução desses adenomas, havendo respostas significativas apenas numa minoria de pacientes. Surpreendentemente, o uso do octreotídeo pode resultar em certa melhora da função visual, sem que haja redução visível do tumor, o que pode decorrer dos seus efeitos vasodilatadores no sistema nervoso central. A combinação de cabergolina em doses altas e de octreotídeo parece obter a redução tumoral num maior número de casos, mas é uma opção terapêutica pouco atraente devido ao seu alto custo e eficácia relativamente baixa.

Mais recentemente, o uso de agonistas dopaminérgicos, preferencialmente logo após o tratamento cirúrgico ou tão logo se observe crescimento do remanescente tumoral, mostrou ser efetivo em estabilizar ou reduzir essas massas, constituindo-se numa estratégia terapêutica interessante para se evitar ou retardar a radioterapia ou a reintervenção cirúrgica (80).

O uso da cintilografia com agonistas dopaminérgicos e somatostatinérgicos marcados com isótopos radioativos e da resposta das gonadotrofinas e/ou sub-unidades ao TRH poderiam auxiliar na seleção de pacientes com maior chance de resposta ao tratamento farmacológico combinado $(85,86)$. É possível que, num futuro próximo, uma maior eficácia no tratamento farmacológico dos adenomas clinicamente não secretores resulte do desenvolvimento de novos análogos da somatostatina.

\section{ADENOMAS TIROTRÓFICOS}

Os adenomas tirotróficos correspondem a cerca de 0,5 a $1 \%$ dos adenomas hipofisários. Acometem igualmente ambos os sexos, com pico de incidência na sexta década de vida, mas a idade do diagnóstico variou entre 11 e 84 anos nos mais de 300 casos de tirotrofinomas publicados na literatura. A hipersecreção tumoral de TSH levando ao hipertiroidismo também pode ocorrer em adenomas mistos ou plurihormonais que co-secretam GH e/ou PRL ou, mais raramente, LH e FSH. A alta prevalência de macroadenomas invasivos ainda observada entre os adenomas secretores de TSH tem declinado ao longo do tempo, provavelmente refletindo maior precocidade 
no diagnóstico devido à inclusão mais rotineira da dosagem de TSH na avaliação laboratorial do hipertiroidismo.

\section{Patologia}

$\mathrm{Na}$ microscopia com coloração convencional, as células dos tirotrofinomas apresentam-se cromófobas, em cordões, polimorfas e com grandes núcleos e nucléolos proeminentes. Na microscopia eletrônica, as células dos tumores bem diferenciados são muito semelhantes aos tirotrofos normais; enquanto as dos tumores pouco diferenciados são angulares e alongadas, com núcleos irregulares, retículo endoplásmico rugoso pouco desenvolvido, longos processos citoplasmáticos e grânulos secretórios esparsos localizados ao longo da membrana celular $(87,88)$. Na imuno-histoquímica, a quase totalidade dos adenomas tirotróficos apresenta expressão de ambas sub-unidades do TSH, mas pode haver desbalanço na produção dessas cadeias, geralmente maior da sub-unidade alfa, e apenas uma delas ser detectável na imuno-histoquímica (89). Alguns adenomas são compostos de dois tipos celulares, um expressando apenas a sub-unidade alfa e a outra coexpressando a sub-unidades alfa e a beta $(90)$.

\section{Patogênese Molecular}

A patogênese dos tirotrofinomas é desconhecida e, devido a sua raridade, existem poucos estudos moleculares nesses tumores. Mutações inativadoras no domínio de ligação do receptor ao hormônio tiroideano foram descritas em dois tirotrofinomas (91), sendo uma delas missense, no mesmo codon de outras duas mutações germinativas descritas em pacientes com síndrome de resistência ao hormônio tiroidiano. A outra, uma deleção de 135 pares de base, cria um sítio novo de splicing alternativo no TR $\gamma-2$. Ambas estão presentes somente no tecido tumoral e prejudicam a ligação do T3 ao receptor TR- $\gamma(91,92)$. Como o desenvolvimento de tirotrofinomas não tem sido observado em pacientes com resistência ao hormônio tiroideano, considera-se que essas mutações não tenham um papel importante na tumorigênese tirotrófica, embora possam estar relacionadas ao mecanismo de resistência tumoral ao feed-back do hormônio tiroideano em alguns casos. Mutações ativadoras no gene do receptor de TRH não têm sido encontradas em tirotrofinomas. Uma redução na expressão de receptores dopaminérgicos foi encontrada em dois adenomas secretores de TSH $(52,53)$.

\section{Quadro Clínico}

O quadro clínico dos pacientes portadores de tirotrofinomas puros é de hipertiroidismo, de severidade va- riável, com bócio difuso ou mesmo multinodular, freqüentemente associado a algum sinal ou sintoma decorrente da compressão tumoral (cefaléia, alteração visual, hipopituitarismo). É ainda relativamente comum que esses pacientes sejam inicialmente diagnosticados como portadores de hipertiroidismo primário e tratados com drogas antitiroideanas, radioiodo e/ou cirurgia tiroideana, o que pode alterar, de forma definitiva, o status tiroideano por ocasião do diagnóstico. Em casos mais raros, os tirotrofinomas podem ser clinicamente silenciosos e diagnosticados como adenomas clinicamente não secretores.

\section{Diagnóstico}

Clinicamente, o diagnóstico de um tirotrofinoma pode ser prontamente suspeitado em pacientes com quadro de hipertiroidismo, bócio e alterações neuro-oftalmológicas sugestivas tumor selar. Na ausência de alterações neuro-oftalmológicas clinicamente evidentes, essa suspeita só é levantada a partir do quadro hormonal: níveis circulantes elevados dos hormônios tiroideanos, preferencialmente o T4 livre, e níveis não suprimidos (normais ou elevados) de TSH, caracterizando o "hipertiroidismo central". No entanto, essas alterações podem decorrer de outras causas mais ou menos raras. Assim, interferências metodológicas em alguns tipos de ensaio podem gerar valores espuriamente elevados de TSH (interferência de anticorpos heterofílicos presentes no soro). $\mathrm{O}$ uso de estrógenos e a hipertiroxinemia familiar causam elevação do T4 total, mas não do livre, pelo aumento da TBG ou pela anormalidade da albumina, respectivamente. Finalmente, a ingestão de tiroxina antes da coleta do sangue pode causar elevação do T4 livre em pacientes com hipotiroidismo primário, sendo que nesses pacientes os níveis de TSH podem estar normais ou mesmo aumentados por tratamento irregular.

Nos adenomas secretores de TSH, é comum a co-secreção da sub-unidade alfa, estando sua concentração sérica e a relação molar com o TSH francamente elevadas na maioria dos casos. A redução da resposta do TSH ao TRH é também bastante característica dos pacientes com tirotrofinomas. $\mathrm{O}$ diagnóstico do tirotrofinoma pode ser concluído, quase que inequivocamente, pelo achado de um adenoma hipofisário na ressonância magnética da sela turca, cabendo lembrar que cerca de $80 \%$ desses tumores são macroadenomas. A possibilidade de esse diagnóstico estar incorreto devido à presença de um incidentaloma num paciente com resistência ao hormônio tiroideano existe, porém é muito pequena e tanto menor quanto maior for o tamanho do tumor encontrado. Dessa 
forma, um diagnóstico diferencial mais aprofundado com a síndrome de resistência ao hormônio tiroideano é frequentemente desnecessária, mas deve ser considerada sempre que não se encontra uma alteração hipofisária convincente na ressonância magnética ou se o paciente tiver história familiar de casos semelhantes, já que tirotrofinomas familiares inexistem e a resistência ao hormônio tiroideano é uma doença predominantemente familiar. Dado o caráter dominante da síndrome de resistência ao hormônio tiroideano, a simples dosagem de TSH e do T4 livre em parentes de primeiro grau (pais, irmãos e filhos) é de grande auxílio na solução desse dilema diagnóstico.

\section{Tratamento}

Uma estratégia terapêutica ideal para os adenomas secretores de TSH ainda não está bem estabelecida. Em parte, isso se deve à raridade desses adenomas, dificultando o acúmulo de experiência e a realização de estudos clínicos comparativos controlados. Em geral, a cirurgia transesfenoidal tem sido a terapêutica mais recomendada para o tratamento inicial dos adenomas secretores de TSH, mas essa prática pode ser questionada, dada a maior disponibilidade e a alta eficácia dos análogos da somatostatina no tratamento desses tumores. Na prática, é comum a utilização de mais de uma modalidade terapêutica para o controle tumoral e hormonal em grande parte dos casos e a estratégia terapêutica deve ser individualizada.

\section{Cirurgia}

Nos macroadenomas que se apresentam com alteração visual, a cirurgia transesfenoidal é indicada como tratamento inicial porque possibilita uma rápida descompressão das vias ópticas e otimiza a recuperação visual. No entanto, o tamanho, a invasividade e a consistência freqüentemente endurecida desses adenomas impedem a ressecção total e a correção hormonal na grande maioria dos casos, tornando necessário o uso de terapêutica complementar.

Nos microadenomas ou nos macroadenomas pequenos, sem extensão extra-selar, que conjuntamente representam a minoria dos casos de tirotrofinomas, a ressecção cirúrgica é recomendável como tratamento inicial porque tem maior chance de ser completa e promover a cura. Contudo, essa indicação só é válida se o neurocirurgião tiver boa experiência em curar outros tipos de microadenomas secretores, que freqüentemente ocorrem em pacientes com doença de Cushing e mais raramente em acromegálicos.

Nos adenomas com extensão extra-selar, mas sem comprometimento visual, a indicação cirúrgica tem sido justificada pela redução do volume tumoral ("debulking") e da secreção de TSH. Os possíveis benefícios de uma cirurgia não curativa nesse grupo de pacientes são o restabelecimento do eutiroidismo em alguns casos, o controle do hipertiroidismo com doses menores de agentes anti-tiroideanos ou de análogos da somatostatina em outros, bem como a redução do campo para a radioterapia. Além disso, a ressecção parcial pode propiciar maior espaço de acomodação intraselar em caso de crescimento do resíduo tumoral, podendo assim reduzir o risco da compressão de outras estruturas, sobretudo do quiasma óptico.

\section{Radioterapia}

A radioterapia tem sido geralmente utilizada como terapia complementar à ressecção cirúrgica incompleta dos tirotrofinomas visando o controle do crescimento tumoral e do hipertiroidismo. Embora a eficácia da radioterapia convencional no tratamento desses tumores pareça menor do que em outros tumores hipofisários, continua a ser amplamente utilizada devido a taxa de cura cirúrgica relativamente baixa e pela inexistência de outros métodos terapêuticos com possibilidade de cura definitiva demonstrada. A radioterapia estereotáxica ("radiocirurgia") poderia ter uma maior eficácia no tratamento dessas lesões residuais, sobretudo em seio cavernoso, mas a experiência com esse método é ainda limitada (93).

\section{Tratamento Farmacológico}

O uso dos análogos da somatostatina tem sido altamente eficaz em reduzir a secreção de TSH, controlar o hipertiroidismo e reduzir ou impedir o crescimento tumoral na maioria dos pacientes portadores de tirotrofinomas $(94,95)$. É interessante notar que a eficácia dos análogos da somatostatina nos adenomas secretores de TSH é até superior à reportada na acromegalia, onde seu emprego como terapia primária vem progressivamente ganhando maior indicação. Os análogos da somatostatina são geralmente bem tolerados, sobretudo os de longa ação como o octreotídeoLAR e o Lanreotídeo. As doses utilizadas do octreotídeo-LAR, o único disponível no país, são semelhantes às utilizadas no tratamento da acromegalia (20 ou $30 \mathrm{mg} / \mathrm{mês}$ via intramuscular). Dada a baixa eficácia terapêutica dos agonistas dopaminérgicos em relação aos análogos da somatostatina no tratamento dos adenomas secretores de TSH em geral, sua utilização, isolada ou em associação ao análogo da somatostatina, pode ser tentada em casos de resistência parcial ou completa aos análogos.

Em pacientes com hipotiroidismo devido a 
tratamento prévio da tiróide por tiroidectomia ou terapia com iodo-radioativo, deve-se administrar tiroxina para manter o eutiroidismo clínico e os níveis de hormônios tiroideanos na faixa normal. Sem a reposição de tiroxina ou com uma reposição insuficiente, esses pacientes apresentam níveis de TSH ainda mais elevados, refletindo secreção aumentada de TSH pelos tirotrofos normais e tumorais frente aos baixos níveis circulantes dos hormônios tiroideanos.

\section{Outras Formas de Tratamento do Hipertirodismo Central}

O controle do hipertiroidismo durante o preparo dos pacientes portadores de tirotrofinomas para a cirurgia hipofisária deve ser feito com antitiroideanos e/ou com análogos de somatostatina. Estudos retrospectivos têm mostrado uma maior prevalência de adenomas em pacientes previamente submetidos à ablação tiroideana, à semelhança do que se observa em alguns pacientes com doença de Cushing tratados com adrenalectomia (síndrome de Nelson) (90). Dessa forma, seria prudente restringir a indicação da tiroidectomia, do iodo-radioativo e mesmo a utilização prolongada de antitiroideanos para controlar o hipertiroidismo em pacientes portadores de adenomas secretores de TSH. Na prática, contudo, como essas são as únicas formas de controlar o hipertiroidismo em casos mais severos, sua indicação deve ser considerada nos casos em que o tratamento dirigido ao tumor não conseguir o controle satisfatório do hipertiroidismo.

\section{REFERÊNCIAS}

1. Black PMcL, Hsu DW, Klibanski A, Kliman B, Jameson JL, Ridgway EC, et al. Hormone production in clinically nonfunctioning pituitary adenomas. J Neurosurg 1987;66: 244-50.

2. Daneshdoost L, Gennarelli TA, Savino PJ, Sergott RC, Bosley TM, Snyder PJ. Recognition of gonadotroph adenomas in women. N Eng J Med 1991;324:589-94.

3. Abucham J, Landman G, Vieira JGH, Chacra AR. Imuno-histoquímica hipofisária: metodologia e aplicação. Arq Bras Endocrinol Metab 1985;29:82-90.

4. Asa SL, Gerrie BM, Singer W, Horvath E, Kovacs K, Smyth HS. Gonadotropin secretion in vitro by human pituitary null cell adenomas and oncocytomas. J Clin Endocrinol Metab 1986;62:1011-8.

5. Jameson JL, Klibanski A, Black PMcL, Zervas NT, Lindell CM, Hsu DW, et al. Glycoprotein hormone genes are expressed in clinically non-functioning pituitary adenomas. J Clin Invest 1987;80:1472-1.

6. Mashiter K, Adams E, van Noorden S. Secretion of LH, FSH and PRL shown by cell culture and immunocytochemistry of human functionless pituitary adenomas.
Clin Endocrinol 1981;15:103-12.

7. Macedo CLD, Alberti V, Mesquita MI, Vieira JGH, Abucham J. A nested case-control study of immunohistochemistry and serum levels of gonadotropins/subunits in clinically nonsecreting pituitary adenomas. Endocr Pathol 1992;3:27-9.

8. Snyder PJ. Gonadotroph cell adenomas of the pituitary. Endocr Rev 1985;6:552-63.

9. Asa SL. The pathology of pituitary tumors. Endocrinol Metab Clin North Am 1999;28:13-43.

10. Galway AB, Hsueh AJW, Daneshdoost L, Zhou M-H, Pavlou SN, Snyder PJ. Gonadotroph adenomas in men produce biologically active follicle-stimulating hormone. J Clin Endocrinol Metab 1990;71:907-12.

11. Turner HE, Nagy Z, Sullivan N, Esiri MM, Wass JA. Expression analysis of cyclins in pituitary adenomas and the normal pituitary gland. Clin Endocrinol (Oxf) 2000;53:337-44.

12. Jordan S, Lidhar K, Korbonits M, Lowe DG, Grossman AB. Cyclin D and cyclin E expression in normal and adenomatous pituitary. Eur J Endocrinol 2000;143(1):R1-6.

13. Heaney AP, Horwitz GA, Wang Z, Singson R, Melmed S. Early involvement of estrogen-induced pituitary tumor transforming gene and fibroblast growth factor expression in prolactinoma pathogenesis. Nat Med 1999;5:1317-21.

14. Zou H, McGarry TJ, Bernal T, Kirschner MW. Identification of a vertebrate sister-chromatid separation inhibitor involved in transformation and tumorigenesis. Science 1999;285:418-22.

15. Zhang X, Horwitz GA, Heaney AP, Nakashima M, Prezant TR, Bronstein MD, et al. Pituitary tumor transforming gene (PTTG) expression in pituitary adenomas. J Clin Endocrinol Metab 1999;84:761-7.

16. Saez C, Japon MA, Ramos-Morales F, Romero F, Segura $\mathrm{DI}$, Tortolero M, et al. hPTTG is over-expressed in pituitary adenomas and other primary epithelial neoplasias. Oncogene 1999; 18:5473-6.

17. Levy A, Lightman S. Molecular defects in the pathogenesis of pituitary tumours. Front Neuroendocrinol 2003;24:94-127.

18. Ikeda H, Yoshimoto T, Shida N, Molecular analysis of p21 and p27 genes in human pituitary adenomas. Br J Cancer 1997;76:1119-23.

19. Takeuchi S, Koeffler HP, Hinton DR, Miyoshi I, Melmed S, Shimon L. Mutation and expression analysis of the cyclin-dependent kinase inhibitor gene p27/Kipl in pituitary tumors. J Endocrinol 1998;157:337-41.

20. Dahia PL, Aguiar RC, Honegger J, Fahlbush R, Jordan S, Lowe DG, et al. Mutation and expression analysis of the p27/kipl gene in corticotrophin-secreting tumours. Oncogene 1998; 16:69-76.

21. Kamb A, Gruis NA, Weaver-Feldhaus J, Liu Q, Harshman $\mathrm{K}$, Tavtigian SV, et al. A cell cycle regulator potentially involved in genesis of many fumor types. Science 1994;264(5157):436-40.

22. Yoshimoto $C$, Tanaka $C$, Yamada S, Kimura T, Iwahana $H$, Sano $T$, et al. Infrequent mutations of pl6INK4A and p15INK4B genes in human pituitary adenomas. Eur $\mathbf{J}$ 


\section{Endocrinol 1997;136:74-80.}

23. Simpson DJ, Bicknell JE, McNicol AM, Clayton RN, Farrell WE. Hypermethylation of the p16/CDKN2A/MTSI gene and loss of protein expression is associated with nonfunctional pituitary adenomas but not somatotrophinomas. Genes Chromosomes Cancer 1999;24:328-36.

24. Cryns VL, Alexander JM, Klibanski A, Arnold A. The retinoblastoma gene in human pituitary tumors. J Clin Endocrinol Metab 1993;77:644-6.

25. Zhu J, Leon SP, Beggs AH, Busque L, Gilliliard DG, Black PM. Human pituitary adenomas show no loss of heterozygosity at the retinoblastoma gene locus. J Clin Endocrinol Metab 1994;78:922-7.

26. Woloschak M, Roberts JL, Post KD. Loss of heterozygosity at the retinoblastoma locus in human pituitary tumors. Cancer 1994;74:693-6.

27. Woloschak M, Yu A, Xiao J, Post KD. Abundance and state of phosphorylation of the $\mathrm{Rb}$ gene product in human pituitary tumors. Int J Cancer 1996;67:16-9.

28. Pei L, Melmed S, Scheithauer B, Kovacs K, Benedict WF, Prager D. Frequent loss of heterozygosity at the retinoblastoma susceptibility gene (RB) locus in aggressive pituitary tumors: evidence for a chromosome 13 tumor suppressor gene other than RB. Cancer Res 1995:55:1613-6.

29. Yonish RE, Resnitzky D, Lotem J, Sachs L, Kimchi A, Oren M. Wild-type p53 induces apoptosis of myeloid leukaemic cells that is inhibited by interleukin-6. Nature 1991;353:345-7.

30. Hollstein M, Sidransky D, Vogelstein B, Harris CC. p53 mutations in human cancers. Science 1991;253:49-53.

31. Levy A, Hall L, Yeudall WA, Lightman SL. p53 gene mutations in pituitary adenomas: rare events. Clin Endocrinol (Oxf) 1994;41:809-14.

32. Pernicone PJ, Scheithauer BW, Sebo TJ, Kovacs KT, Horvath E, Young WJ, et al. Pituitary carcinoma: a clinicopathologic study of 15 cases. Cancer 1997;79:804-12.

33. Spengler D, Villalba M, Hoffmann A, Pantaloni C, Houssami S, Bockaert J, et al. Regulation of apoptosis and cell cycle arrest by Zacl, a novel zinc finger protein expressed in the pituitary gland and the brain. EMBO J 1997:16:2814-25.

34. Pagotto U, Arzberger T, Theodoropoulou M, Grubler Y, Pantaloni C, Saeger W, et al. The expression of the antiproliferative gene ZAC is lost or highly reduced in nonfunctioning pituitary adenomas. Cancer Res 2000;60:6794-9.

35. Spada A, Arosio M, Bochicchio D, Bazzoni N, Vallar L, Bassetti $M$, et al. Clinical, biochemical, and morphological correlates in patients bearing growth hormonesecreting pituitary tumors with or without constitutively active adenylyl cyclase. J Clin Endocrinol Metab. 1990:7:1421-6.

36. Yoshimoto K, Iwahana H, Fukuda A, Sano T, Itakura M. Rare mutations of the Gs alpha subunit gene in human endocrine tumors. Mutation detection by polymerase chain reaction-primer-introduced restriction analysis. Cancer 1993;72:1386-93.

37. Williamson EA, Daniels M, Foster S, Kelly WF, Kendall-Tay-
Ior P, Harris PE. Gs $\gamma$ and $\mathrm{Gi} 2 \gamma$ mutations in clinically nonfunctioning pituitary tumours. Clin Endocrinol (Oxf) 1994;41:520-815.

38. Williamson EA, Ince PG, Harrison D, Kendall-Taylor P, Harris PE. G-protein mutations in human pituitary adrenocorticotrophic hormone-secreting adenomas. Eur J Clin Invest 1995;25:28-131.

39. Oyesiku NM, Evans CO, Brown MR, Blevins LS, Tindall GT, Parks JS. Pituitary adenomas: screening for $G_{\gamma} q$ mutations. J Clin Endocrinol Metab 1997;82:4184-8.

40. Schiemann U, Assert R, Moskopp D, Gellner R, Hengst K, Gullotta $\mathrm{F}$, et al. Analysis of a protein kinase $\mathrm{C}-\gamma$ mutation in human pituitary tumours. J Endocrinol 1997; 153:131-7.

41. Korytko Al, Fields AP, Allshouse LA, Cuttler L. Pituitary expression of protein kinase $C$ isotypes during early development. J Neuroendocrinol 1999;10:569-76.

42. Couldwell WT, Law RE, Hinton DR, Gopalakrishna R, Yong VW, Weiss MH. Protein kinase $C$ and growth regulation of pituitary adenomas. Acta Neurochir Suppl (Wien) 1996;65:22-6.

43. Jin J, Maeda T, Chandler WF, Lloyd RV. Protein kinase C (PKC) activity and PKC messenger RNAs in human pituitary adenomas. Am J Pathol 1993; 142:569.

44. Todo T, Buchfelder $M$, Thierauf $P$, Fahlbusch R. Immunohistochemical expression of protein kinase $C$ type III in human pituitary adenomas. Neurosurgery 1993;32:542635.

45. Alvaro V, Touraine P, Raisman Vozari R, Bai-Grenier F, Birman $P$, Joubert D. Protein kinase $C$ activity and expression in normal and adenomatous human pituitaries. Int J Cancer 1992;50(5):724-30.

46. Alvaro V, Lévy L, Dubray C, Roche A, Peillon F, Quérat B, et al. Invasive human pituitary tumors express a pointmutated a-protein kinase-C. J Clin Endocrinol Metab 1993:77:1125-9.

47. Lei T, Xue D, Adams EF, Buchfelder M, Fahlbusch R. Relationship between invasiveness of pituitary somatotrophinomas and structural abnormalities of protein kinase $C$ gene in human. J Tongji Med Univ 1997;17(2):68-71.

48. Friedman E, Adams EF, Höög A, Gejman PB, Carson E, Larsson $C$, et al. Normal structural dopamine type 2 receptor gene in prolactin-secreting and other pituitary tumors. J Clin Endocrinol Metab 1994;78:568-74.

49. Koga M, Nakao H, Arao M, Sato B, Noma K, Morimoto $Y$, et al. Demonstration of specific dopamine receptors on human pituitary adenomas. Acta Endocrinol (Copenh) 1987;114:595-602.

50. Salvatori R, Thakker RV, Lopes MB, Fan X, Eswara JR, Ellison $D$, et al. Absence of mutations in the growth hormone $(\mathrm{GH})$-releasing hormone receptor gene in $\mathrm{GH}$ secreting pituitary adenomas. Clin Endocrinol (Oxf) 2001:54:301-7.

51. Hashimoto K, Koga M, Motomura T, Kasayama S, Kouhara $\mathrm{H}$, Ohnishi $\mathrm{T}$, et al. Identification of alternatively spliced messenger ribonucleic acid encoding truncated growth hormone-releasing hormone receptor in human pituitary adenomas. J Clin Endocrinol Metab 1995;80:2933-9. 
52. Dong Q, Brucker-Davis $F$, Weintraub BD, Smallridge RC, Carr FE, Battey J, et al. Screening of candidate oncogenes in human thyrotroph tumors: absence of activating mutations of the $G_{\gamma} q, G_{\gamma} 11, G_{\gamma} s$, or thyrotropinreleasing hormone receptor genes. J Clin Endocrinol Metab1 996;81:1134-40.

53. Collu R, Tang J, Castagne J, Lagace G, Masson N, Huot $C$, et al. A novel mechanism for isolated central hypothyroidism: inactivating mutations in the thyrotropin-releasing hormone receptor gene. J Clin Endocrinol Metab 1997;82:1561-5.

54. Jaffrain-Rea ML, Petrangeli E, Ortolani F, Fraioli B, Lise A, Esposito V, et al. Cellular receptors for sex steroids in human pituitary adenomas. J Endocrinol 1996,151:17584.

55. Chaidarun SS, Klibanski A, Alexander JM. Tumor-specific expression of alternatively spliced estrogen receptor messenger ribonucleic acid variants in human pituitary adenomas. J Clin Endocrinol Metab 1997;82:1058-65.

56. Melmed S. Mechanisms for pituitary fumorigenesis: the plastic pituitary. J Clin Invest 2003; 1 12:1603-18.

57. Shupnik MA. Oestrogen receptors, receptor variants and oestrogen actions in the hypothalamic-pituitary axis. J Neuroendocrinol 2002; 14:85-94.

58. Gittoes NJ, McCabe CJ, Sheppard MC, Franklyn JA. Estrogen receptor $\gamma$ RNAm expression in normal and adenomatous pituitaries. Pituitary 1999;1:99-104.

59. Fujiwara K, Ikeda $\mathrm{H}$, Yoshimoto $\mathrm{T}$. Abnormalities in expression of genes, RNAm, and proteins of transforming growth factor- $\gamma$ receptor type I and type II in human pituitary adenomas. Clin Neuropathol 1998;17:19-26.

60. Abbass SA, Asa SL, Ezzat S. Altered expression of fibroblast growth factor receptors in human pituitary adenomas. J Clin Endocrinol Metab 1997;82:1160-6.

61. Lowe WL, Pestell RG, Madison LD, Jameson JL. Mechanisms of hormone action. In: Jameson JL, editor. Principles of Molecular Medicine. New Jersey:Humana Press Inc, 1998.p.419-31.

62. Weiner RI, Windle J, Mellon P, Schechter J. Role of FGF in tumorigenesis of the anterior pituitary. J Endocrinol Invest 1991;14(suppl. 1):10.

63. Zimering MB, Katsumata N, Sato Y, Brandi ML, Aurbach GD, Marx SJ, et al. Increased basic fibroblast growth factor in plasma from multiple endocrine neoplasia type 1: relation to pituitary tumor. J Clin Endocrinol Metab 1993;76:1182-7.

64. Shimon I, Melmed S. Pituitary tumor pathogenesis. J Clin Endocrinol Metab 1997;82:1675-81.

65. Shimon I, Huttner A, Said J, Spirina O, Melmed S. Heparin-binding secretory transforming gene (hst) facilitates rat lactotrope cell tumorigenesis and induces prolactin gene transcription. J Clin Invest 1996;97:187-95.

66. Herman V, Drazin NZ, Gonsky R, Melmed S. Molecular screening of pituitary adenomas for gene mutations and rearrangements. J Clin Endocrinol Metab 1993;77:50-5.

67. Shimon I, Hinton DR, Weiss MH, Melmed S. Prolactinomas express human heparin-binding secretory transforming gene (hst) protein product: marker of tumour invasiveness. Clin Endocrinol (Oxf) 1998;48:23-9.
68. Fukino K, Kitamura Y, Sanno N, Teramoto A, Emi M. Analysis of the MEN1 gene in sporadic pituitary adenomas from Japanese patients. Cancer Lett 1999;144:8592.

69. Evans CO, Brown MR, Parks JS, Oyesiku NM. Screening for MEN1 tumor suppressor gene mutations in sporadic pituitary tumors. J Endocrinol Invest 2000;23:304-9.

70. Zhuang Z, Ezzat SZ, Vortmeyer AO, Weil R, Oldfield EH, Park WS, et al. Mutations of the MEN1 tumor suppressor gene in pituitary tumors. Cancer Res 1997;57:5446-51.

71. Zhang $X$, Sun H, Danila DC, Johnson SR, Zhou Y, Swearingen $B$, et al. Loss of expression of GADD45 $\gamma$, a growth inhibitory gene, in human pituitary adenomas: implications for tumorigenesis. J Clin Endocrinol Metab 2002;87:1262-7.

72. Oppenheim DS, Kana AR, Sangha JS, Klibanski A. Prevalence of alpha-subunit hypersecretion in patients with pituitary tumors: clinically nonfunctioning and somatotroph adenomas. J Clin Endocrinol Metab 1990;70:859-64.

73. Vieira JGH, Noguti KO, Macedo CD, Abucham J, Nishida SK, Weffort RVB, et al. Desenvolvimento de um ensaio imunométrico para a dosagem sérica da subunidade alfa dos hormônios glicoprotêicos. Arq Bras Endocrinol Metab 1993;37:69-74.

74. Vieira JGH, Nishida SK, Lombardi MT, Abucham J, Kasamatsu TS. Monoclonal antibodies specific for free alpha-subunit of glycoprotein hormones and their use in the development of a sensitive immunofluorimetric assay. Braz J Med Biol Res 1995;28:633-6.

75. Chong BW, Newton TH. Hypothalamic and pituitary pathology. Radiol Clin North Am 1993;31:1 147-83.

76. Abucham J, Oliveira JHA, Nogueira RG. Avaliação e tratamento das massas selares. In: Antunes-Rodrigues, ed. Neuroendocrinologia básica e aplicada. São Paulo:Guanabara Koogan, 2005.p.515-48.

77. Donovan LE, Corenblum B. The natural history of the pituitary incidentaloma. Arch Intern Med 1995;155:1813.

78. Ebersold MJ, Quast LM, Laws ER, Scheithauer B, Randall $\mathrm{RV}$. Long-term results in transsphenoidal removal of nonfunctioning pituitary adenomas. J Neurosurg 1986;64:713-9.

79. Arafah BM. Reversible hypopituitarism in patients with large nonfunctioning pituitary adenomas. J Clin Endocrinol Metab 1986;62:1173-9.

80. Greenman Y, Tordjman K, Osher E, Veshchev I, Shenkerman G, Reider-Groswasse II, et al. Postoperative treatment of clinically nonfunctioning pituitary adenomas with dopamine agonists decreases tumour remnant growth. Clin Endocrinol 2005;63:39-44.

81. Jackson IMD, Norén $G$. Role of gamma knife therapy in the management of pituitary tumors. Endocrinol Metab Clin North Am 1999;28:133-42.

82. Shomali ME, Katznelson L. Medical therapy for gonadotroph and thyrotoph fumors. Endocrinol Metab Clin North Am 1999;28:223-40.

83. Colao A, Di Sarno A, Marzullo P, Di Somma C, Cerbone $G$, Landi ML, et al. New medical approaches in pituitary 
adenomas. Horm Res 2000;53(suppl. 3):76-87.

84. Hofland LJ, Lamberts SW. Somatostatin receptors in pituitary function, diagnosis and therapy. Front Horm Res 2004;32:235-52.

85. Broson-Chazot F, Houzard C, Ajzemberg C, Nocaudie $M$, Duet $M$, Mundler $O$, et al. Somatostatin receptor imaging in somatotroph and non-functioning pituitary adenomas: correlation with hormonal and visual responses to octreotide. Clin Endocrinol (Oxf) 1997;47:589-98.

86. Andersen M, Bjerre $P$, Scroder HD, Edal A, HoilundCarlsen PF, Pedersen $\mathrm{PH}$, et al. In vivo secretory potential and the effect of combination therapy with noctreotide and cabegoline in patients with clinically nonfunctioning pituitary adenomas. Clin Endocrinol (Oxf) 2001;54:23-30.

87. Bertholon-Grégoire M, Trouillas J, Guigard MP, Loras B, Tourniaire J. Mono- and plurihormonal thyrotropic pituitary adenomas: pathological, hormonal and clinical studies in twelve patients. Eur $J$ Endocrinol 1999; 140:519-27.

88. Sanno N, Teramoto A, Osamura RY. Thyrotropin secreting pituitary adenomas. Clinical and biological heterogeneity and current treatment. J Neurooncol 2001:54:179-86.

89. Maccagnan P, Chacra AR, Abucham J. Marked imbalance between $\gamma$ - and $\gamma$-TSH subunit in a pituitary adenoma resulting in hyperthyroidism with normal TSH and high $\gamma$-TSH levels and extremely high $\gamma$-SU/TSH molar ratios. Arq Bras Endocrinol Metab 1994;38(supl. 2): 182.

90. Beck-Peccoz P, Brucker-Davis F, Persani L, Smallridge RC, Weintraub $B$. thyrotropin secreting pituitary tumors. Endocr Rev 1996;17:610-38.
91. Ando S, Sarlis NJ, Oldfield EH, Yen PM. Somatic Mutation of TR $\gamma$ can cause a defect in negative regulation of TSH in a TSH-secreting pituitary tumor. $J$ Clin Endocrinol Metab 2001;86:5572-6.

92. Ando S, Sarlis NJ, Krishnan J, Feng X, Refetoff S, Zhang $M Q$, et al. Aberrant alternative splicing of thyroid hormone receptor in a TSH-secreting pituitary tumor is a mechanism for hormone resistance. Mol Endocrinol 2001;15:152-38.

93. Brucker-Davis F, Oldfield EH, Skarulis MC, Doppman JL, Weintraub BD. Thyrotropin-secreting pituitary tumors: diagnostic criteria, thyroid hormone sensitivity and treatment outcome in 25 patients followed at the National Institutes of Health. J Clin Endocrinol Metab 1999;84:476-86.

94. Caron P, Arlot S, Bauters C, Chanson P, Kuhn JM, Pugeat $M$, et al. Efficacy of the long-acting octreotide formulation (octreotide-LAR) in patients with thyrotropin-secreting pituitary adenomas. J Clin Endocrinol Metab 2001;86:2849-53.

95. Beck-Peccoz P, Persani L. Medical management of thyrotropin-secreting pituitary adenomas. Pituitary 2002;5:83-8.

Endereço para correspondência:

Julio Abucham

Rua Pedro de Toledo 910

04039-002 São Paulo, SP

Fax: (11) 5579-6636

E-mail: julioabucham@uol.com.br 